ARTICLE

\title{
Benchmark Calculations of Sodium-Void Experiments with Uranium Fuels at the Fast Critical Assembly FCA
}

\author{
Masahiro FUKUSHIMA*, Yasunori KITAMURA, Teruhiko KUGO, Tsuyoshi YAMANE, \\ Masaki ANDOH, Go CHIBA, Makoto ISHIKAWA and Shigeaki OKAJIMA
}

Japan Atomic Energy Agency, 2-4 Shirakata, Tokai-mura, Naka-gun, Ibaraki-ken, 319-1195, Japan

\begin{abstract}
The capture cross section of ${ }^{235} \mathrm{U}$ has been re-evaluated by the OECD/NEA/NSC/WPEC Subgroup 29 focusing on energy region from $100 \mathrm{eV}$ to $1 \mathrm{MeV}$ from the viewpoints of differential and integral data analyses since 2007. Sodium-void reactivity experiments with uranium fuels were carried out at the Fast Critical Assembly (FCA) in the Japan Atomic Energy Agency (JAEA) in 2009 and new integral data were obtained to help to validate the re-evaluated capture cross section of ${ }^{235} \mathrm{U}$.

The benchmark specification for the sodium-void reactivity experiments is given. The detailed benchmark calculations for the new integral data were performed by using a continuous-energy Monte Carlo code (MVP) with use of the evaluated nuclear data libraries JENDL-3.2, -3.3, -4.0, ENDF/B-VII.0 and JEFF-3.1. The MVP calculations were performed with 2,000,000,000 particles. The statistical uncertainties of the MVP calculations were within several percents of the measured sodium-void reactivities. The ratios of calculated to experimental (C/E) values of sodium-void reactivities with respect to JENDL-3.3, ENDF/B-VII.0 and JEFF-3.1 are less than those with respect to JENDL-3.2 and -4.0. The analysis results are similar to those of sodium-void reactivities previously obtained at the BFS facility which is another fast critical assembly in Russia. The benchmark calculations demonstrate the improvement of the reliability of the integral data such as the new integral data obtained at the FCA and the previously obtained data in the BFS and the usefulness of the new integral data for the validation of the re-evaluated cross section of ${ }^{235} \mathrm{U}$. In addition, the benchmark tests with various correction factors by a deterministic calculation system are summarized for the help to validate the re-evaluated capture cross section of ${ }^{235} \mathrm{U}$.
\end{abstract}

KEYWORDS: sodium-void reactivity experiment, uranium, cross section, FCA, Monte Carlo

\section{Introduction}

The cross sections of ${ }^{235} \mathrm{U}$ were examined by the working party on international nuclear data evaluation co-operation (WPEC) under the nuclear science committee (NSC) of OECD/NEA as the activity of the subgroup 18 focusing on the thermal and the epithermal energy regions. ${ }^{1)}$ As a result, the Oak Ridge National Laboratory (ORNL) group evaluated the resolved resonance parameters of ${ }^{235} \mathrm{U}$ up to 2.25 $\mathrm{keV}$, which have been recently used for major libraries such as JENDL-3.3, ${ }^{2)}$ ENDF/B-VII.0 ${ }^{3)}$ and JEFF-3.1. ${ }^{4)}$ Using the resolved resonance parameters evaluated, prediction accuracy of neutronic characteristics has been satisfactory for thermal reactors. However, recent benchmark analyses have revealed a problem regarding the capture cross section of ${ }^{235} \mathrm{U}$ for fast-neutron critical experiments at the BFS facility of Institute of Physics and Power Engineering (IPPE) in Russia and at the Fast Critical Assembly (FCA) of the Japan Atomic Energy Agency (JAEA) using uranium fuels. ${ }^{5}$ Among the existing libraries, JENDL-3.3, ENDF/B-VII.0 and JEFF-3.1 cannot describe the criticalities and the sodium-void reactivities for these critical assemblies. This problem is attributable to large capture cross section of ${ }^{235} \mathrm{U}$ in energy region from $100 \mathrm{eV}$ to $2.25 \mathrm{keV}$ where the resolved resonance parameters evaluated are used. Moreover,

*Corresponding author, E-mail: fukushima.masahiro@jaea.go.jp

(C) 2011 Atomic Energy Society of Japan, All Rights Reserved. in the energy region from $30 \mathrm{keV}$ to $1 \mathrm{MeV}$, there exists a big difference in ${ }^{235} \mathrm{U}$ capture cross sections between JENDL-3.3 and ENDF/B-VII.0. The WPEC is to address these problems on the ${ }^{235} \mathrm{U}$ capture cross section from the viewpoints of differential and integral data analyses and then obtains recommended cross section in energy region from $100 \mathrm{eV}$ to $1 \mathrm{MeV}$ as the activity of the subgroup 29. In order to obtain new integral data to help the validation of the re-evaluated ${ }^{235} \mathrm{U}$ capture cross sections, sodium-void reactivity experiments with uranium fueled core were carried out at the FCA in 2009. The purpose of the present study is to prepare the benchmark specification of the sodium-void reactivity experiments and to perform benchmark calculations. Detailed benchmark calculations were performed by using a continuous-energy Monte Carlo code, $\mathrm{MVP}^{6)}$ with geometry models made as detailed as possible. The measured data were analyzed with the existing libraries JENDL-3.2, ${ }^{7)}$-3.3, -4.0, ${ }^{8)}$ ENDF/B-VII.0, JEFF-3.1. The newest JENDL-4.0 was just released on May 28th, 2010. This paper presents an introduction of new integral data obtained at the FCA, the results of the benchmark calculations and the comparison between them. In Appendix, the benchmark tests with various correction factors by a deterministic calculation are given. 


\section{Experiment}

\section{Core Characteristics}

The FCA is a horizontal table-split type assembly consisting of fixed and movable halves. These half assemblies are separated for fuel loading, and are brought together for operation. The sodium-void reactivity experiments with uranium fuels were carried out with the FCA-XXVII core series. The cores were coupled systems comprising a central core zone and surrounding blanket zones. Figure 1 gives an $\mathrm{R}-\mathrm{Z}$ cross-sectional view of the fixed half assembly of the XXVII core. The core zone was composed of low and high enriched uranium metals and graphite (EU-C region). The average enrichment of the core zone was approximately $30 \%$. The height of the core zone was approximately $61 \mathrm{~cm}$. In the radial direction, the core zone is surrounded by two radial blanket zones; the inner blanket zone of approximately $30 \mathrm{~cm}$ thickness contains a significant amount of depleted uranium dioxide and sodium, and the outer blanket zone of approximately $20 \mathrm{~cm}$ thickness contains only depleted uranium block.

\section{Measurement of Sodium-Void Reactivity Worth}

The test zone was set up at the center of the core zone with changing the height as listed in Table 1. Figures 2(a) and (b) give X-Y cross-sectional views of the XXVII core for Case- 1 and for Cases-2 and -3, respectively. A couple of half fuel drawers (that contain EU-CLR region) were added in the core zone for Cases- 2 and -3 . The equivalent radii of the core zones are also given in Table 1 . The test zone was composed of low and high enriched uranium metals and canned sodium (EU-NA region). The EU-NA at the test zone was replaced with the EU-VOID where canned sodium in the EU-NA were altered to voided steel cans to evaluate the sodium-void reactivities. Table 2 gives the homogenized atomic number densities of the regions shown in Fig. 1. For Cases-1 and -2, the reactivities were measured by using the control rods that were calibrated beforehand. For Case-3, the reactivity was measured by adopting the source multiplication method. The effective delayed neutron fraction $\beta_{\text {eff }}(=0.00754 \pm 0.00027)$ was evaluated with JENDL-3.3. The error of $\beta_{\text {eff }}$ was evaluated by its covariance data of $v_{\mathrm{d}}{ }^{2)}$ The measured sodium-void reactivities are summarized in Table 3 together with the experimental errors. One sees that the relative errors were about a few percents. They were small enough to distinguish the differences of the calculated results among the libraries which were observed in the BFS experiments.

Table 1 Core specifications for measurements

\begin{tabular}{cccc}
\hline Case & $\begin{array}{c}\text { Height of } \\
\text { test zone } \\
\left(\mathrm{z}_{\mathrm{t}} \times 2\right)[\mathrm{cm}]\end{array}$ & $\begin{array}{c}\text { Equivalent radius of } \\
\text { test zone }[\mathrm{cm}]\end{array}$ & $\begin{array}{c}\text { Equivalent radius of } \\
\text { core zone }\left(\mathrm{r}_{\mathrm{c}}\right)[\mathrm{cm}]\end{array}$ \\
\hline Case-1 & $5.08 \times 2$ & 9.34 & 31.30 \\
Case-2 & $10.16 \times 2$ & 9.34 & 31.45 \\
Case-3 & $15.24 \times 2$ & 9.34 & 31.45 \\
\hline
\end{tabular}

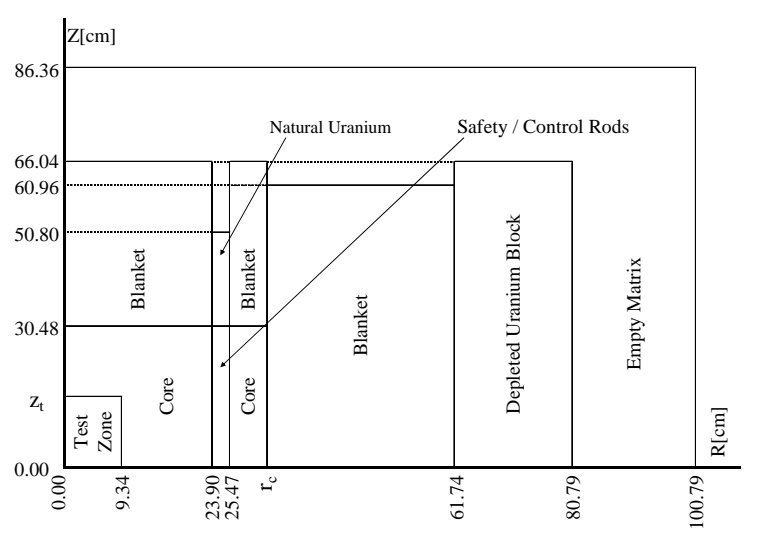

Fig. 1 R-Z cross sectional view of XXVII core (Height of test zone $2 z_{t}$ and equivalent radius of core zone $r_{c}$ are given in Table 1)

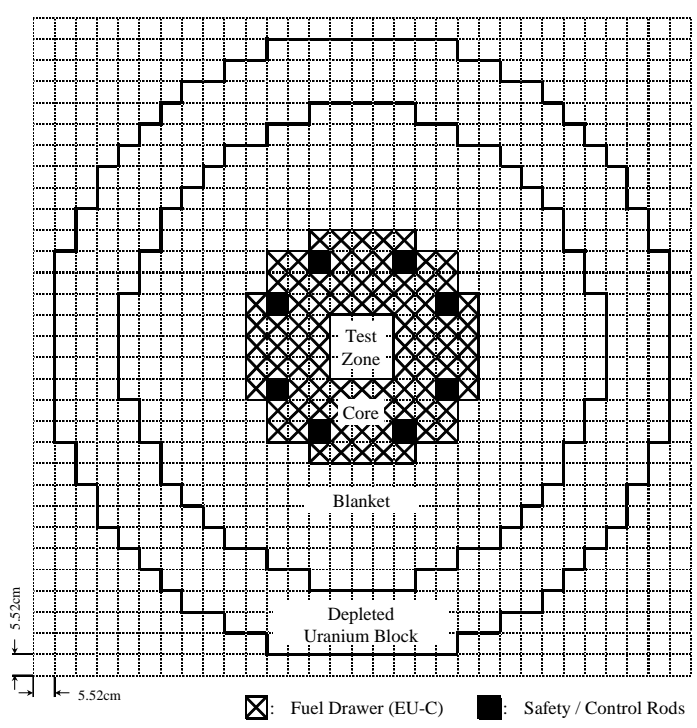

(a) Case-1

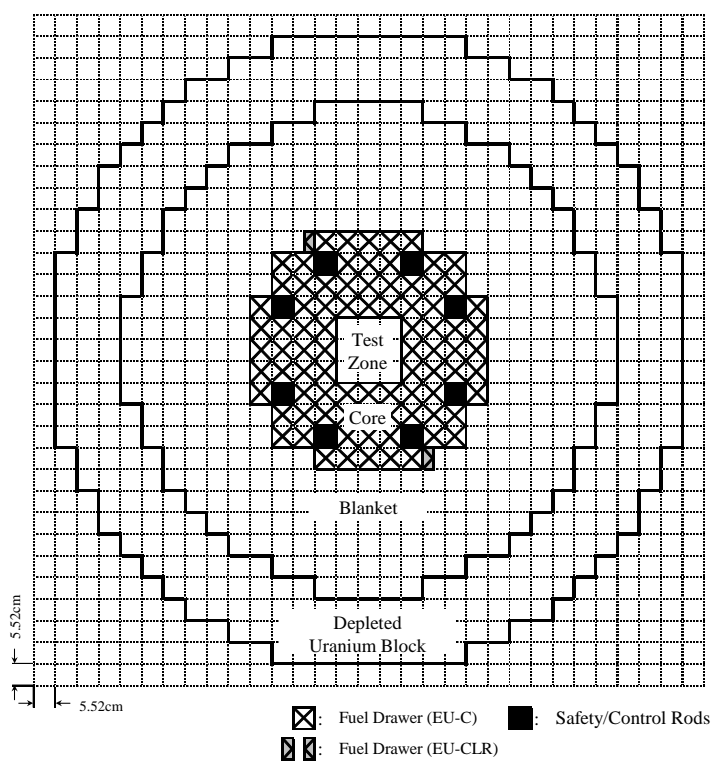

(b) Cases-2 and -3

Fig. 2 X-Y cross sectional views of XXVII core 
Table 2 Atomic number density of homogenized cell for FCA-XXVII $\quad\left[10^{24}\right.$ atoms $\left./ \mathrm{cm}^{3}\right]$

\begin{tabular}{|c|c|c|c|c|c|c|c|c|c|}
\hline \multirow{2}{*}{$\begin{array}{l}\text { Region } \\
\text { name }\end{array}$} & \multicolumn{2}{|c|}{ Test Zone } & \multicolumn{2}{|c|}{ Core } & \multirow{2}{*}{$\begin{array}{c}\text { Safety / } \\
\text { Control } \\
\text { Rods }\end{array}$} & \multirow{2}{*}{$\begin{array}{l}\text { Natural } \\
\text { Uranium }\end{array}$} & \multirow[b]{2}{*}{ Blanket } & \multirow{2}{*}{$\begin{array}{c}\text { Depleted } \\
\text { Uranium } \\
\text { Block }\end{array}$} & \multirow{2}{*}{$\begin{array}{l}\text { Empty } \\
\text { Matrix }\end{array}$} \\
\hline & EU-NA & EU-VOID & EU-C & EU-CLR & & & & & \\
\hline $\mathrm{H}-1$ & $8.864 \mathrm{E}-05$ & 8.864E-05 & $1.043 \mathrm{E}-04$ & $1.152 \mathrm{E}-04$ & $1.020 \mathrm{E}-04$ & 3.124E-05 & & 5.139E-05 & \\
\hline B-10 & $1.050 \mathrm{E}-08$ & $1.052 \mathrm{E}-08$ & 3.054E-09 & 3.054E-09 & 2.545E-09 & & & & \\
\hline B-11 & 3.822E-08 & 3.827E-08 & $1.230 \mathrm{E}-08$ & $1.230 \mathrm{E}-08$ & $1.025 \mathrm{E}-08$ & & & & \\
\hline C-nat. & $9.627 \mathrm{E}-05$ & $9.630 \mathrm{E}-05$ & 5.255E-02 & $5.256 \mathrm{E}-02$ & 5.062E-02 & 2.621E-05 & & 4.313E-05 & \\
\hline $\mathrm{N}-14$ & $3.986 \mathrm{E}-07$ & $3.986 \mathrm{E}-07$ & 3.986E-07 & $4.476 \mathrm{E}-07$ & 3.986E-07 & $1.403 \mathrm{E}-07$ & & 2.311E-07 & \\
\hline O-16 & 3.839E-05 & 3.839E-05 & 4.622E-05 & $5.094 \mathrm{E}-05$ & 4.508E-05 & 1.353E-05 & 1.843E-02 & $2.226 \mathrm{E}-05$ & \\
\hline F-19 & 2.939E-05 & 2.939E-05 & 2.939E-05 & 3.300E-05 & 2.939E-05 & $1.036 \mathrm{E}-05$ & & $1.704 \mathrm{E}-05$ & \\
\hline $\mathrm{Na}-23$ & $1.180 \mathrm{E}-02$ & & & & & & 7.656E-03 & & \\
\hline Si-nat. & $9.363 \mathrm{E}-05$ & $9.375 \mathrm{E}-05$ & $1.338 \mathrm{E}-07$ & $1.338 \mathrm{E}-07$ & $1.115 \mathrm{E}-07$ & & & & \\
\hline P-31 & 5.603E-06 & 5.611E-06 & & & & & & & \\
\hline S-nat. & $4.920 \mathrm{E}-07$ & $4.926 \mathrm{E}-07$ & & & & & & & \\
\hline Cr-nat. & 3.670E-03 & 3.673E-03 & $1.810 \mathrm{E}-03$ & $1.810 \mathrm{E}-03$ & $2.518 \mathrm{E}-03$ & $1.810 \mathrm{E}-03$ & 3.117E-03 & $1.810 \mathrm{E}-03$ & $1.229 \mathrm{E}-03$ \\
\hline Mn-55 & $1.998 \mathrm{E}-04$ & $1.999 \mathrm{E}-04$ & $1.203 \mathrm{E}-04$ & $1.203 \mathrm{E}-04$ & 1.673E-04 & 1.203E-04 & 2.297E-04 & 1.203E-04 & 8.167E-05 \\
\hline Fe-nat. & $1.321 \mathrm{E}-02$ & $1.322 \mathrm{E}-02$ & $6.472 \mathrm{E}-03$ & $6.472 \mathrm{E}-03$ & $9.001 \mathrm{E}-03$ & 6.472E-03 & 1.122E-02 & 6.472E-03 & 4.393E-03 \\
\hline Ni-nat. & $1.539 \mathrm{E}-03$ & $1.540 \mathrm{E}-03$ & 7.893E-04 & 7.893E-04 & $1.098 \mathrm{E}-03$ & 7.893E-04 & 1.413E-03 & 7.893E-04 & 5.357E-04 \\
\hline Nb-93 & $5.661 \mathrm{E}-07$ & $5.668 \mathrm{E}-07$ & & & & & & & \\
\hline Mo-nat. & $1.206 \mathrm{E}-05$ & $1.208 \mathrm{E}-05$ & & & & & & & \\
\hline U-235 & $2.836 \mathrm{E}-03$ & $2.836 \mathrm{E}-03$ & $2.836 \mathrm{E}-03$ & $3.718 \mathrm{E}-03$ & $2.836 \mathrm{E}-03$ & 2.891E-04 & 1.869E-05 & 8.432E-05 & \\
\hline U-238 & $6.872 \mathrm{E}-03$ & $6.872 \mathrm{E}-03$ & $6.872 \mathrm{E}-03$ & $5.989 \mathrm{E}-03$ & 6.872E-03 & 3.988E-02 & 9.199E-03 & 4.014E-02 & \\
\hline
\end{tabular}

Table 3 Measured sodium-void reactivities

\begin{tabular}{cc}
\hline Case & Sodium-void reactivity $\left[\times 10^{-3} \Delta k / k k^{\prime}\right]$ \\
\hline Case-1 & $-0.40 \pm 0.02^{*}$ \\
Case-2 & $-0.80 \pm 0.03^{*}$ \\
Case-3 & $-1.22 \pm 0.08^{*}$ \\
\hline
\end{tabular}

*: Experimental errors

Table 4 Calculated sodium-void reactivities and C/E values

\begin{tabular}{clcc}
\hline Case & \multicolumn{1}{c}{ Library } & $\begin{array}{c}\text { MC calculations } \\
{\left[\times 10^{-3} \Delta k / k k^{\prime}\right]}\end{array}$ & C/E \\
\hline \multirow{5}{*}{ Case-1 } & JENDL-3.2 & $-0.479 \pm 0.020^{*}$ & $1.20 \pm 0.09^{* *}$ \\
& JENDL-3.3 & $-0.310 \pm 0.020^{*}$ & $0.78 \pm 0.07^{* *}$ \\
& JENDL-4.0 & $-0.480 \pm 0.020^{*}$ & $1.20 \pm 0.09^{* *}$ \\
& ENDF/B-VII.0 & $-0.248 \pm 0.020^{*}$ & $0.62 \pm 0.06^{* *}$ \\
& JEFF-3.1 & $-0.318 \pm 0.020^{*}$ & $0.79 \pm 0.07^{* *}$ \\
\hline \multirow{5}{*}{ Case-2 } & JENDL-3.2 & $-0.827 \pm 0.020^{*}$ & $1.03 \pm 0.05^{* *}$ \\
& JENDL-3.3 & $-0.574 \pm 0.020^{*}$ & $0.72 \pm 0.04^{* *}$ \\
& JENDL-4.0 & $-0.908 \pm 0.020^{*}$ & $1.13 \pm 0.05^{* *}$ \\
& ENDF/B-VII.0 & $-0.528 \pm 0.020^{*}$ & $0.66 \pm 0.04^{* *}$ \\
& JEFF-3.1 & $-0.617 \pm 0.020^{*}$ & $0.77 \pm 0.04^{* *}$ \\
\hline \multirow{5}{*}{ Case-3 } & JENDL-3.2 & $-1.336 \pm 0.020^{*}$ & $1.09 \pm 0.07^{* *}$ \\
& JENDL-3.3 & $-1.032 \pm 0.020^{*}$ & $0.85 \pm 0.06^{* *}$ \\
& JENDL-4.0 & $-1.374 \pm 0.020^{*}$ & $1.13 \pm 0.07^{* *}$ \\
& ENDF/B-VII.0 & $-0.907 \pm 0.020^{*}$ & $0.74 \pm 0.05^{* *}$ \\
& JEFF-3.1 & $-0.997 \pm 0.020^{*}$ & $0.82 \pm 0.05^{* *}$ \\
\hline
\end{tabular}

*: Statistical uncertainties of Monte Carlo calculations

**: Statistical uncertainties of MC calculations and the experimental errors

\section{Benchmark Calculation}

The sodium-void reactivities were analyzed with the use of the existing libraries JENDL-3.2, -3.3, -4.0, ENDF/B-VII.0 and JEFF-3.1 by using a continuous-energy Monte Carlo code MVP with geometry models made as detailed as possible. The reactivities were obtained from $\left(k_{\text {eff }}^{\prime}-k_{\text {eff }}\right) / k_{\text {eff }} k_{\text {eff }}^{\prime}$, where $k_{\text {eff }}$ and $k_{\text {eff }}^{\prime}$ were the effective multiplication factors of cores with EU-NA and EU-VOID, respectively. The calculated sodium-void reactivities using the MVP calculations together with the statistical uncertainties are shown in Table 4. In this table, the ratios of calculation to experimental $(\mathrm{C} / \mathrm{E})$ values together with the uncertainties of the calculations are also summarized. The MVP calculations were performed with 2,000,000,000 particles. The statistical uncertainties of the MVP calculations were within several percents of the measured sodium-void reactivities. These were small enough to distinguish the differences of the calculated results among the major libraries. One understands from this table that the $\mathrm{C} / \mathrm{E}$ values of sodium-void reactivities with respect to JENDL-3.3, ENDF/B-VII.0 and JEFF-3.1 are less than those with respect to JENDL-3.2 and -4.0. This tendency of the C/E values is similar to those for the sodium-void reactivity experiments using uranium fuels at the BFS facility. In BFS cores with uranium fuels, the sodium-void reactivities were sensitive to the ${ }^{235} \mathrm{U}$ capture cross sections at $\mathrm{keV}$ energy region, where a big difference exists among major nuclear data libraries.

\section{Sensitivity Analysis}

A sensitivity analysis was carried out to investigate the differences among the libraries. The sensitivity coefficients were calculated based on the diffusion theory by using a generalized perturbation code, SAGEP ${ }^{9)}$ and JENDL-4.0 library. Here, a homogeneous model was adopted. Figure 3 shows sensitivity coefficients of the sodium-void reactivities to ${ }^{235} \mathrm{U}$ capture cross section. For all cases, the reactivities are sensitive in $\mathrm{keV}$ energy region of ${ }^{235} \mathrm{U}$ capture cross section. 


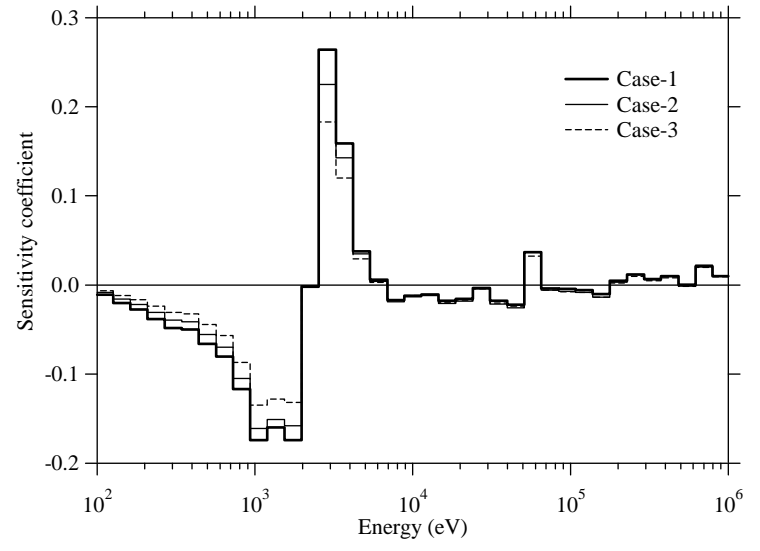

Fig. 3 Sensitivity of sodium-void reactivity to ${ }^{235} \mathrm{U}$ capture cross section

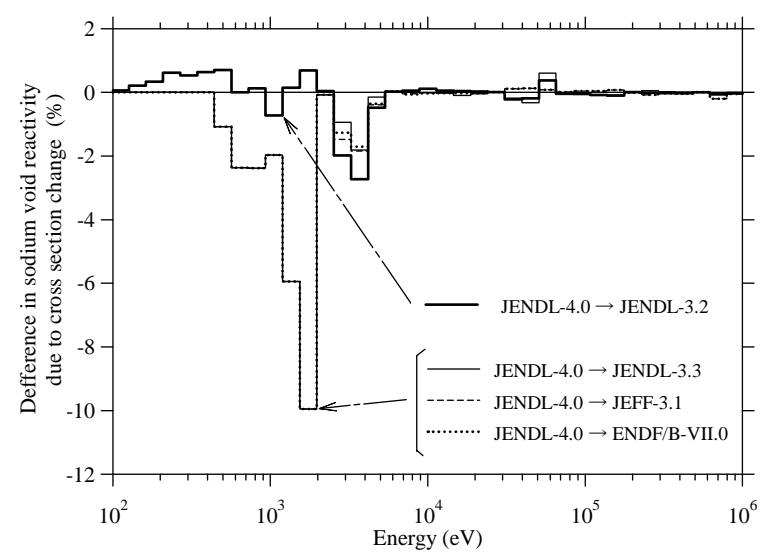

Fig. 4 Energy-wise contribution of ${ }^{235} \mathrm{U}$ capture cross section to sodium-void reactivity change for Case-2

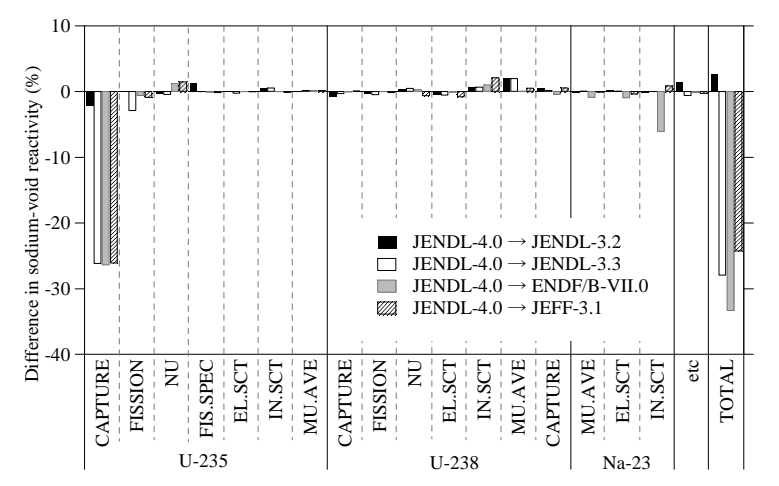

Fig. 5 Nuclide-wise contribution to sodium-void reactivity change for Case-2

Figure 4 shows energy-wise contribution of ${ }^{235} U$ capture cross section to the sodium-void reactivity change from JENDL-4.0 to other libraries for Case-2. We can find that the differences with respect to JEFF-3.1, JENDL-3.3 and ENDF/B-VII.0 are much larger than that with respect to JENDL-3.2. Figure 5 shows nuclide-wise contributions to the sodium-void reactivity change from JENDL-4.0 to other libraries. We can find that the difference of ${ }^{235} U$ capture cross sections contributes mainly to the sodium-void reactivity change. The total differences from JENDL-4.0 to JENDL-3.3, ENDF/B-VII.0 and JEFF-3.1 are up to about $28 \%, 33 \%$ and $24 \%$, respectively. The tendency is consistent with the results by the Monte Carlo calculations. It was clarified that the main cause explaining the difference among libraries was the capture cross section of ${ }^{235} U$.

\section{Conclusion}

New integral data of the sodium-void reactivity with uranium fueled cores were obtained at the FCA of the JAEA in 2009. The benchmark specification of the experiments is prepared. The detailed benchmark calculations were performed by using a continuous-energy Monte Carlo code (MVP) with use of the existing libraries JENDL-3.2, -3.3, -4.0, ENDF/B-VII.0 and JEFF-3.1. The statistical uncertainties of the MVP calculations were within several percents of the measured sodium-void reactivities. The new integral data reproduce the similar tendency of the C/E values among the libraries to those of the previous experiments at the BFS in Russia. From the sensitivity analysis, it was clarified that the sodium-void reactivities are sensitive in $\mathrm{keV}$ energy region of ${ }^{235} \mathrm{U}$ capture cross section. Since the similar results are independently obtained, it can be said that the new integral data obtained at the FCA improve the reliability of the existing integral data both for the FCA and the BFS. Therefore, the new integral data can be used to help the validation of the re-evaluated capture cross sections of ${ }^{235} \mathrm{U}$ and will contributes to the compilation of new versions of the libraries and the activity of the subgroup-29 under WPEC of OECD/NEA with benchmark tests of the new integral data by a deterministic calculation system, which are given in Appendix.

\section{Acknowledgment}

The authors wish to express their gratitude to the FCA staff for their support in conducting the experiment. The authors express special thanks to the members of the subgroup-29 of WPEC, especially Drs. O. Iwamoto and T. Nakagawa for their valuable information about the experiments and encouraging us.

\section{References}

1) C. R. Lubitz, R. W. Roussin, Epithermal capture cross-section of ${ }^{235} U$, A report by the Working Party on International Evaluation Co-operation of the NEA Nuclear Science Committee, NEA/WPEC-18 International Evaluation Co-operation Volume 18, Nuclear Energy Agency (NEA), Organization for Economic Co-operation and Development (OECD) (1999).

2) K. Shibata, T. Kawano, T. Nakagawa et al., "Japanese evaluated nuclear data library version 3 revision-3: JENDL-3.3,” $J$. Nucl. Sci. Technol., 39, 1125 (2002).

3) P. Oblozinsky, M, Herman, "Special issue on evaluated nuclear data file ENDF/B-VII.0,” Nucl. Data Sheets, 107, 2931 (2006).

4) A. Koning, R. Forrest, M. Kellett et al., The JEFF-3.1 Nu- 
clear Data Library, JEFF Report 21, OECD/NEA Data Bank (2006).

5) M. Ishikawa, "Recent application of nuclear data to fast reactor core analysis and design in Japan," Proc. Int. Conf. on Nucl. Data for Sci. and Technol. (ND2004), Santa Fe, New Mexico, Sep. 26 - Oct. 1, Am. Inst. of Phys., 1405, (2005).

6) Y. Nagaya, K. Okumura, T. Mori et al., MVP/GMVP II: General purpose Monte Carlo codes for neutron and photon transport calculations based on continuous energy and multigroup methods, JAERI 1348, Japan Atomic Energy Research Institute (JAERI) (2005).

7) T. Nakagawa, K. Shibata, S. Chiba et al., "Japanese evaluated nuclear data library version 3 revision-2: JENDL-3.2,” $J$. Nucl. Sci. Technol., 32, 1259 (1995).

8) K. Shibata, O. Iwamoto, T. Nakagawa et al., "JENDL-4.0: A New Library for Nuclear Science and Engineering," J. Nucl. Sci. Technol., 48, 1 (2011).

9) A. Hara, T. Takeda, Y. Kikuchi, SAGEP: Two-dimensional sensitivity analysis code based on generalized perturbation theory, JAERI-M 84-027, Japan Atomic Energy Research Institute (JAERI) (1984), [in Japanese].

10) T. Hazama, G. Chiba, K. Sugino, "Development of a Fine and Ultra-Fine Group Cell Calculation Code SLAROM-UF for Fast Reactor Analyses,”. J. Nucl. Sci. Technol., 43, 908 (2006).

11) T. B. Fowler, et al., Nuclear reactor analysis code: CITATION, ORNL-TM-2496 Rev.2, Oak Ridge National Laboratory (ORNL) (1971).

12) T. Yamamoto, T. Takeda, Y Sasaki, Y. Saito et al., "Three-Dimensional Transport Correction in Fast Reactor Core Analysis,” J. Nucl. Sci. Technol., 23, 849 (1986).

13) S. Iijima, H. Yoshida, H. Sakuragi, Calculation program for fast reactor design, 2(Multi-dimensional perturbation theory code based on diffusion approximation: PERKY), JAERI-M 6993 Japan Atomic Energy Research Institute (JAERI) (1977).

14) K. Nakano et al., User's Manual of SNPERT-3D Code, PNC ZJ9270 94-003, JNC Report, Japan Atomic Energy Agency (JAEA) (1994), [in Japanese].

15) T. Tone, "A numerical study of heterogeneity effects in fast reactor critical assemblies,” J. Nucl. Sci. Technol., 12, 467 (1975).

16) P. Benoist, "Streaming effects and collision probabilities in lattices,” Nucl. Sci. Eng., 34, 285-307 (1968).

\section{Appendix}

Additionally, the benchmark tests by a deterministic calculation system were performed for the new integral data. The deterministic calculation codes used in the analysis are the following:

\begin{tabular}{cll}
\hline Cell calculation & \multicolumn{1}{c}{ SLAROM-UF $^{10)}$} & \\
Core calculation & CITATION-FBR & Diffusion \\
& TRITAC $^{12)}$ & Transport \\
\hline \multirow{2}{*}{ Perturbation calculation } & PERKY $^{13)}$ & Diffusion \\
& SNPERT-3D $^{14)}$ & Transport \\
\hline
\end{tabular}

The core calculation by the diffusion theory can be performed by using XYZ models shown in Fig. 2. To compare the calculation results with the experimental results correction factors were applied. The correction factors were prepared for JENDL-3.2, -3.3, -4.0, ENDF/B-VII.0 and
JEFF-3.1. The correction factors were evaluated by the exact perturbation method, since the sodium-void reactivity consists of various components. The components are generally classified into two terms, i.e., the non-leakage and leakage ones. The correction factors were prepared for the respective two terms. Table 5 summarizes the calculation methods to evaluate the correction factors and definitions of them.

In method-1 which was the base calculation method, the effective macroscopic cross sections for each region were prepared to take account of the resonance self-shielding effect in infinite homogeneous media. The cell and core calculations in method-1 were performed by 70 energy groups (lethargy width: 0.25 in energy range from $0.3 \mathrm{eV}$ to $10 \mathrm{MeV}$ ) and commonly used in all calculation methods except for method-5. The core calculation was performed by the XYZ models and commonly used in all the calculation methods. The mesh intervals in the core calculation were $2.76 \mathrm{~cm}$ in the $\mathrm{X}$ - and $\mathrm{Y}$ - directions, and $2.54 \mathrm{~cm}$ in the Z-direction and commonly used in all the calculation methods.

In method-2 which was used for the evaluation of the correction factor of "Hetero/Homo", the cell calculation was performed in the one-dimensional slab heterogeneous geometry. The effective cross sections for the heterogeneous cells were evaluated by using Tone's method. ${ }^{15)}$ The cell averaged macroscopic cross sections were produced by the flux weighting based on the flux distribution obtained by the collision probability method. The diffusion coefficient was defined by the average of the anisotropic diffusion coefficients based on the Benoist's formula. ${ }^{16)}$

In methods-3 and -4 which were used for the evaluation of the correction factor of "Transport", the cell calculations were performed in the one-dimensional slab heterogeneous geometry. The correction factor was evaluated by a ratio of the result of $S_{N}$ transport calculation to that of diffusion calculation. The $\mathrm{S}_{\mathrm{N}}$ transport calculation is performed with the $S_{8}$ quadrature set and with the transport cross section defined by the extended transport approximation. The diffusion coefficient was defined by one third of the inverse of the transport cross section used in the transport calculation.

In method-5 which was used for the evaluation of the correction factor of "Ultrafine", the cell calculation was performed in the one-dimensional slab heterogeneous geometry. The resonance self-shielding was evaluated by the collision probability method with a ultrafine energy group structure. The correction factor was evaluated by a ratio of the result of method-5 to that of method-2.

In method-6 which was used for the evaluation of the correction factor of "Aniso/Iso", the diffusion coefficients were defined by the anisotropic diffusion coefficients based on Benoist's formula. The correction factor was evaluated by a ratio of the result of method- 6 to that of method-2. The correction by “Aniso/Iso” was negligibly small. Moreover, the difference between method-2 and method-4 was also negligibly small.

Thus obtained correction factors are listed in Table 6. 
The correction factors for the non-leakage and leakage terms were applied independently for corresponding terms of the base calculation. The final sodium-void reactivity is evaluated by summing up the corrected non-leakage and the corrected leakage terms. The correction factors by JENDL-3.3, ENDF/B-VII.0 and JEFF-3.1 have different tendencies from those by JENDL-3.2 and -4.0. The difference would be due to the discrepancies of the capture cross section of ${ }^{235} \mathrm{U}$ among these libraries. It is recommended to use the correction factors by the corresponding library. The calculation results are summarized in Table 7.

The deterministic calculation also shows similar tendency with the results by the Monte Carlo calculation in the comparison among JENDL-3.2, -3.3, -4.0, ENDF/B-VII.0 and JEFF-3.1. The corrected results agree with the Monte Carlo calculation results within $3 \sigma$ of statistical uncertainties.

Table 5 Deterministic calculation methods and definitions of correction factors

\begin{tabular}{|c|c|c|c|c|c|}
\hline Method & Cell model & Energy group for cell calc. & Energy groups for core calc. & & Theory \\
\hline 1 & Homo & 70 & 70 & Diffution: & $1 /\left(3 \Sigma_{t r}\right)$ \\
\hline 2 & Hetero & 70 & 70 & Diffution: & Average of Benoist's D: $2 / 3 \mathrm{D}_{/ /}+1 / 3 \mathrm{D}_{\perp}$ \\
\hline 3 & Hetero & 70 & 70 & Transport: & $\mathrm{S}_{8} \mathrm{P}_{0}\left(\Sigma_{t r}\right)$ \\
\hline 4 & Hetero & 70 & 70 & Diffution: & $1 /\left(3 \Sigma_{t r}\right)$ \\
\hline 5 & Hetero & Ultrafine & 175 & Diffution: & Average of Benoist's D: $2 / 3 \mathrm{D}_{/ /}+1 / 3 \mathrm{D}_{\perp}$ \\
\hline 6 & Hetero & 70 & 70 & Diffution: & Benoist's D: $\mathrm{D}_{/ /}, \mathrm{D}_{\perp}$ \\
\hline \multicolumn{2}{|c|}{ Correction factor : } & $\begin{array}{l}\text { "Hetero/Homo" = method- } \\
\text { "Ultrafine group" = method }-\end{array}$ & $\begin{array}{l}\text { thod-1 } \\
\text { thod-2 }\end{array}$ & \multicolumn{2}{|c|}{$\begin{array}{l}\text { "Transport" = method }-3 / \text { method }-4 \\
\text { "Aniso/Iso" = method }-6 / \text { method }-2\end{array}$} \\
\hline
\end{tabular}

Table 6 Correction factors of deterministic calculation for sodium-void reactivity

\begin{tabular}{|c|c|c|c|c|c|c|c|c|c|}
\hline \multirow{2}{*}{ Case } & \multirow{2}{*}{ Library } & \multicolumn{2}{|c|}{ Hetero/Homo } & \multicolumn{2}{|c|}{ Ultrafine group } & \multicolumn{2}{|c|}{ Transport } & \multicolumn{2}{|c|}{ Aniso/Iso } \\
\hline & & Non-leak & Leakage & Non-leak & Leakage & Non-leak & Leakage & Non-leak & Leakage \\
\hline \multirow{5}{*}{ Case-1 } & JENDL-3.2 & 1.117 & 1.022 & 0.924 & 1.021 & 0.941 & 0.747 & 1.000 & 0.997 \\
\hline & JENDL-3.3 & 1.217 & 1.013 & 0.870 & 1.033 & 0.905 & 0.748 & 1.000 & 0.997 \\
\hline & JENDL-4.0 & 1.111 & 1.025 & 0.946 & 1.028 & 0.945 & 0.750 & 1.000 & 0.996 \\
\hline & ENDF/B-VII.0 & 1.214 & 1.016 & 0.839 & 1.041 & 0.908 & 0.745 & 1.000 & 0.997 \\
\hline & JEFF-3.1 & 1.188 & 1.017 & 0.858 & 1.034 & 0.928 & 0.751 & 1.000 & 0.996 \\
\hline \multirow{4}{*}{ Case-2 } & JENDL-3.2 & 1.114 & 1.022 & 0.924 & 1.019 & 0.939 & 0.784 & 1.000 & 1.000 \\
\hline & JENDL-4.0 & 1.108 & 1.024 & 0.943 & 1.027 & 0.943 & 0.786 & 1.000 & 1.000 \\
\hline & ENDF/B-VII.0 & 1.197 & 1.018 & 0.854 & 1.036 & 0.909 & 0.782 & 1.000 & 1.000 \\
\hline & JEFF-3.1 & 1.172 & 1.019 & 0.866 & 1.029 & 0.929 & 0.787 & 1.000 & 1.000 \\
\hline \multirow{4}{*}{ Case-3 } & JENDL-3.2 & 1.111 & 1.018 & 0.924 & 1.012 & 0.937 & 0.787 & 0.999 & 1.003 \\
\hline & JENDL-3.3 & 1.195 & 1.013 & 0.876 & 1.018 & 0.903 & 0.788 & 0.999 & 1.003 \\
\hline & JENDL-4.0 & 1.105 & 1.019 & 0.942 & 1.017 & 0.942 & 0.789 & 0.999 & 1.004 \\
\hline & ENDF/B-VII.0 & 1.187 & 1.015 & 0.860 & 1.022 & 0.909 & 0.785 & 0.999 & 1.003 \\
\hline
\end{tabular}

Table 7 Summary of deterministic and Monte Carlo calculations

\begin{tabular}{|c|c|c|c|c|c|c|c|c|c|c|}
\hline \multirow{3}{*}{ Case } & \multirow{3}{*}{ Library } & \multicolumn{6}{|c|}{ Deterministic calculations $\left[\times 10^{-3} \Delta k / k k^{\prime}\right]$} & \multirow{3}{*}{$\mathrm{C} / \mathrm{E}$} & \multirow{3}{*}{$\begin{array}{l}\text { MC calculations } \\
{\left[\times 10^{-3} \Delta k / k k^{\prime}\right]}\end{array}$} & \multirow{3}{*}{$\mathrm{C} / \mathrm{E}$} \\
\hline & & $\mathrm{Ba}$ & e calculati & & & rected resu & & & & \\
\hline & & Non-leak & Leakage & Total & Non-leak & Leakage & Total & & & \\
\hline \multirow{5}{*}{ Case- 1} & JENDL-3.2 & -0.388 & -0.070 & -0.457 & -0.377 & -0.054 & -0.431 & 1.08 & $-0.479 \pm 0.020^{*}$ & $1.20 \pm 0.09 * *$ \\
\hline & JENDL-3.3 & -0.239 & -0.077 & -0.316 & -0.229 & -0.060 & -0.289 & 0.72 & $-0.310 \pm 0.020 *$ & $0.78 \pm 0.07 * *$ \\
\hline & JENDL-4.0 & -0.407 & -0.069 & -0.476 & -0.404 & -0.054 & -0.459 & 1.15 & $-0.480 \pm 0.020 *$ & $1.20 \pm 0.09 * *$ \\
\hline & ENDF/B-VII.0 & -0.220 & -0.068 & -0.287 & -0.204 & -0.053 & -0.256 & 0.64 & $-0.248 \pm 0.020 *$ & $0.62 \pm 0.06 * *$ \\
\hline & JEFF-3.1 & -0.255 & -0.077 & -0.331 & -0.241 & -0.060 & -0.301 & 0.75 & $-0.318 \pm 0.020 *$ & $0.79 \pm 0.07 * *$ \\
\hline \multirow{5}{*}{ Case-2 } & JENDL-3.2 & -0.701 & -0.162 & -0.863 & -0.678 & -0.132 & -0.810 & 1.01 & $-0.827 \pm 0.020 *$ & $1.03 \pm 0.05^{* *}$ \\
\hline & JENDL-3.3 & -0.442 & -0.179 & -0.621 & -0.420 & -0.147 & -0.567 & 0.71 & $-0.574 \pm 0.020 *$ & $0.72 \pm 0.04 * *$ \\
\hline & JENDL-4.0 & -0.740 & -0.161 & -0.901 & -0.729 & -0.133 & -0.863 & 1.08 & $-0.908 \pm 0.020 *$ & $1.13 \pm 0.05^{* *}$ \\
\hline & ENDF/B-VII.0 & -0.415 & -0.155 & -0.570 & -0.385 & -0.128 & -0.513 & 0.64 & $-0.528 \pm 0.020 *$ & $0.66 \pm 0.04 * *$ \\
\hline & JEFF-3.1 & -0.480 & -0.177 & -0.657 & -0.452 & -0.146 & -0.598 & 0.75 & $-0.617 \pm 0.020 *$ & $0.77 \pm 0.04 * *$ \\
\hline \multirow{5}{*}{ Case-3 } & JENDL-3.2 & -0.977 & -0.423 & -1.400 & -0.939 & -0.344 & -1.280 & 1.05 & $-1.336 \pm 0.020 *$ & $1.09 \pm 0.07 * *$ \\
\hline & JENDL-3.3 & -0.625 & -0.450 & -1.070 & -0.591 & -0.367 & -0.957 & 0.78 & $-1.032 \pm 0.020 *$ & $0.85 \pm 0.06^{* *}$ \\
\hline & JENDL-4.0 & -1.030 & -0.422 & -1.460 & -1.010 & -0.347 & -1.360 & 1.11 & $-1.374 \pm 0.020 *$ & $1.13 \pm 0.07 * *$ \\
\hline & ENDF/B-VII.0 & -0.594 & -0.401 & -0.995 & -0.550 & -0.328 & -0.878 & 0.72 & $-0.907 \pm 0.020 *$ & $0.74 \pm 0.05^{* *}$ \\
\hline & JEFF-3.1 & -0.684 & -0.447 & -1.130 & -0.641 & -0.366 & -1.010 & 0.83 & $-0.997 \pm 0.020^{*}$ & $0.82 \pm 0.05^{* *}$ \\
\hline
\end{tabular}

$*$ : Statistical uncertainties of Monte Carlo calculations

**: Statistical uncertainties of MC calculations and the experimental errors 